\title{
Developing Monthly Hydrometeorological Timeseries Forecasts To Reservoir Operation in a Transboundary River Catchment
}

\section{Hammad Ur Rehman}

University of Engineering and Technology

ljaz Ahmad ( $\nabla$ dr.ijaz@uet.edu.pk)

University of Engineering and Technology

Faraz ul Haq

University of Engineering and Technology

Waseem Muhammad

University of Engineering and Technology

Jinxin Zhang

Zhejiang University of Water Resources and Electric Power

\section{Research Article}

Keywords: hydrometeorological, reservoir, river

Posted Date: July 13th, 2021

DOI: https://doi.org/10.21203/rs.3.rs-651687/v1

License: (c) (1) This work is licensed under a Creative Commons Attribution 4.0 International License. Read Full License 


\title{
Developing monthly hydrometeorological timeseries forecasts to reservoir operation in a transboundary river catchment
}

\author{
Hammad-ur-Rehman ${ }^{1}$, Ijaz Ahmad ${ }^{1 *}$, Faraz-ul-Haq ${ }^{1}$, Muhammad Waseem ${ }^{1}$, Jinxin Zhang ${ }^{2}$ \\ Centre of Excellence in Water Resources Engineering, University of Engineering and \\ Technology, Lahore 54890, Pakistan \\ 2 College of Water Resources and Environmental Engineering, Zhejiang University of \\ Water Resources and Electric Power, Hangzhou 310018, China
}

*Corresponding Author Email: dr.ijaz@uet.edu.pk

\begin{abstract}
Forecasting of hydrometeorological timeseries data play vital role in flood forecasting and predicting the future water availability for various uses such as irrigation, hydropower generation, industrial, domestic, etc. Therefore, present study aims to forecast the hydrometeorological timeseries data, i.e., river inflows, precipitation, and evaporation for the improved reservoir operation of a transboundary Mangla catchment by using ARIMA (autoregressive integrated moving average) model. Prior to applying the ARIMA model, stationarity of hydrometeorological timeseries data was checked. Moreover, ACF and PACF of timeseries were determined to determine the " $p$ " and " $q$ " terms of the ARIMA model. The best fitted structure of ARIMA model was used by evaluating the $\mathrm{R}^{2}$, MAE and RMSE to forecast the hydrometeorological timeseries. The seasonal ARIMA structure of $(1,0,0)(2,1,2)_{12}$ was found best fitted for the inflow timeseries whereas ARIMA structures of $(14,1,15)$ and $(9,1,19)$ were considered for forecasting the precipitation and evaporation timeseries, respectively. An average water shortage of $14 \%$ was detected by using these forecasted hydrometeorological timeseries in the reservoir operation during the period of 2016-2030. It was also observed that inflows into Mangla reservoir have seasonal effect more prominent compared to evaporation and precipitation. However, variations in the precipitation timeseries were found less smooth than the inflows timeseries. It is believed that the results of this study may support reservoir operators and managers for developing efficient real-rime reservoir operation policies and strategies based on the variations in the future water availability.
\end{abstract}

\section{Introduction}

In ancient times, human civilization built the towns and cities at places where water was easily available to them for their survival. However, due to rapid increase in population, water requirements go on increasing. To resolve this issue, artificial water conservation structures, i.e., dams and reservoirs were built to fulfil the needs of human activities. These reservoirs can be used for different purposes such as irrigation, recreation, ground water recharging and hydropower, etc. (Sarwar 2013). The economy of many countries in the world has based on these reservoirs especially in arid and semi-arid regions. In arid and semi-arid regions, water availability is decreasing continuously to meet the ever-increasing agricultural demands.

As the water availability is decreasing at alarming rate to fulfil the water demands of various sectors, i.e., domestic, industry, agriculture, etc. Therefore, efficient use of water is necessary to meet these ever-increasing demands (Pulido-Calvo et al. 2003). Better understanding of variations in the hydrometeorological time series data can play an important role in performing the efficient reservoir operation. The phenomena of global warming and climate change is affecting the trends of hydrometeorological time series data, i.e., streamflow, precipitation and evaporation (Musa 2013). The variations in streamflow are very complex in nature. Different models were used to determine these variations in previous studies. The forecasted models are most important for water management to fulfil the needs of crops and mitigation of floods. The forecasted models are used to predict the future water availabilities and to extend the data trends and complete the missing values (Zamani Sabzi, King, and Abudu 2017). In case of reservoir operation, the forecasted inflows have key importance because accurate inflow prediction is not only an important non-engineering measure to ensure flood-control safety and increase water resource use efficiency, but also can provide guidance in reservoir planning and management, because streamflow had the major input into reservoirs. The design of water resources projects is mainly dependent on the stream flows and its duration. Therefore, researchers have more interest in streamflow's forecasting. Rainfall-runoff 
models, GCM models and stochastic models can be used for the prediction of stream flows (Bahremand and De Smedt 2010; Xu et al. 2014; S. Wang et al. 2008; J. Wang et al. 2019).

Mostly stochastic models are used for the prediction of stream flows and analyzing the variations in river runoff (Koutsoyiannis 2000; Lawrance and Kottegoda 1977). Among different stochastic models, autoregressive integrated moving average (ARIMA) stochastic models and autoregressive moving average (ARMA) models are widely used especially in river flow forecasting (Adnan et al. 2017). These stochastic models are also known as Box-Jenkins linear stochastic models (Box et al. 2015). These models are widely used because of their capability to model and forecast a high variety of stationary and non- stationary time series (Brown and Berthouex 2002). These are also capable to estimate serial correlations and trends in a time series data (Gocheva-Ilieva et al. 2014). Moreover, these models can be incorporated into many software packages including SPSS, MINITAB, STATA, R, Python, Matlab and Mathematica, (Comparison of Statistical Packages, 2015).

(Adhikary, Rahman, and Gupta 2012) used seasonal ARIMA model and concluded that SARIMA model can be used to model the groundwater variations. (Valipour et al. 2013) used SARIMA and ARMA models to model the inflow of Dez dam reservoir and concluded that SARIMA model yields better results as compared to ARMA model. (Modarres and Ouarda 2013) demonstrated heteroscedasticity of streamflow time series by ARIMA model in comparison of GARCH models and showed that ARIMA model performed better than GARCH model. (Kurunç, Yürekli, and Çevik 2005) used ARIMA model for forecasting the streamflow data of Yesilurmah River. Various other studies also proved the effectiveness of ARIMA stochastic model as compared to other models (Tayyab et al. 2016; Ahmad, Khan, and Parida 2001; Kurunç, Yürekli, and Çevik 2005)

Pakistan is an agricultural country. Most of its land is irrigated with the canal irrigation systems. Two major reservoirs (Mangla and Tarbela) are considered as the backbone of this irrigation system. The prediction of water availability is helpful to regulate the flows efficiently. The reservoir should be empty or partially empty before the extreme inflow events. Otherwise water storage level exceeds the safe limits and causes floods. To avoid these situations a reliable forecasting of hydrometeorological data is essential. The forecasted hydrometeorological timeseries are considered very helpful in managing the reservoir operation and satisfy the water demands of various sectors. Therefore, this study aims to forecast the hydrometeorological data of the reservoir and used in reservoir operation model to develop future water allocation scenarios. The statistical forecasted models are more famous in research community due to its accuracy and efficiency. Especially ARIMA model is considered most suitable for linear and seasonal timeseries forecasting. Whereas ANN is considered suitable for nonlinear timeseries. Therefore, in this study hydrometeorological timeseries is forecasted by using ARIMA model. The forecasted timeseries are used in reservoir operation to determine the fluctuations in the reservoir storage. It is believed that the results of present study may guide the reservoir operators and managers to predict the future uncertainties in hydrometeorological timeseries data.

\section{Study area}

Mangla reservoir is second largest reservoir of Pakistan. It is located in Mirpur district of Azad and Jammu Kashmir as shown in Figure 1. It is constructed on Jhelum river in 1967. Its 45\% catchment lies in Pakistan occupied Kashmir and remaining is the territory of Indian occupied Kashmir. The Mangla reservoir covers an area of $329.7 \mathrm{~km}^{2}$. The gross storage capacity of reservoir is $9.22 \mathrm{~km}^{3}$. The command area of Mangla reservoir is $60,000 \mathrm{~km}^{2}$. The temperature variation of air is $18{ }^{\circ} \mathrm{C}$ to $43{ }^{\circ} \mathrm{C}$. The primary purpose of Mangla reservoir is to irrigate the agricultural lands. The Mangla reservoir supplies water to the upper and lower Chasma-Jhelum link canal regions. During the period of December to March (Rabi seasons) the irrigation demands are at their peak from for upper Jhelum region for which the water supplied from Mangla reservoir. Mean monthly inflows and precipitation is shown in Figure 2. The excess water from lower and upper Jhelum region irrigates to the lower Indus basin. Hydropower is produced as by product as the water released from the reservoir for any purpose passes through the turbines and its hydropower capacity is 1000 MW (Mega Watt). Mangla domestic demand is 4.2 million gallons of water per day.

\section{[Insert Fig. 1]}

\section{[Insert Fig. 2]}

\section{Materials and Methods}

To Forecast hydrometeorological timeseries ARIMA model was used. Hydrometeorological timeseries should be stationery otherwise it should be converted into stationary. Model identification was performed, and parameters $p, d$, and $q$ were estimated. These estimated parameters were used to forecast the timeseries. The forecasted timeseries incorporated into reservoir operation model. The future water availability scenarios were determined. 


\subsection{Formulation of ARIMA model}

\subsubsection{Data analysis}

Timeseries data analysis was performed to check its trend, extreme and mean monthly values. These factors are also included into the simulated timeseries. Basically, timeseries analysis is the understanding of the data either it is reliable or not. In the ARIMA model, the stationary condition of timeseries is necessary before forecasting the hydrometeorological data.

\subsubsection{Stationary test}

Data stationarity is an essential property of all timeseries of ARIMA otherwise it is required to be converted into stationary timeseries. It means that the ARIMA model only works on the stationary timeseries. The timeseries is considered stationary if its mean E(at), variance $\operatorname{Var}($ at) and covariance Cov (at, at-1) are constant.

\subsubsection{Differencing}

If the timeseries is not stationary, then take the differencing and convert into the stationary. Differencing continues until it converts into stationary, it means $2^{\text {nd }}$ order differencing, $3^{\text {rd }}$ order differencing.

\subsection{Model identification}

The model identification depended on the three terms " $A R$ " $(p)$, order of differencing $(d)$ and " $M A$ " $(q)$ terms. The value " $p$ " is identified by autocorrelation function (ACF). If the value of ACF of timeseries is equal to zero or near to zero, " $p$ " value is considered satisfied. Similarly, the PACF is used to determine the " $q$ " value. " $d$ " represented the degree of differencing to make stationary of timeseries.

\subsubsection{Auto Correlation Function (ACF)}

A timeseries " $a_{n}$ " lagged by " $k$ " times. Its autocorrelation function defined as

$$
A C F \quad r_{k}=\frac{\sum_{t=1}^{n-k}\left(a_{t}-\bar{a}\right)\left(a_{t-k}-\bar{a}\right)}{\sum_{t=1}^{n}\left(a_{t}-\bar{a}\right)^{2}}
$$

\subsubsection{Partial Autocorrelation Function (PACF)}

Partial autocorrelation function (PACF) is used to determine the degree of association between the " $a_{t}$ " and " $a_{t-k}$ " and it can be evaluated from the following formula.

$$
r_{k k}=\left\{\begin{array}{cc}
r_{1} & k=1, \\
\frac{r_{k}-\sum_{j=1}^{k-1} r_{k-1, j} \cdot r_{k-j}}{1-\sum_{j=1}^{k-1} r_{k-1, j} \cdot r_{k}} & \text { if } k=2,3, \mathrm{~K}
\end{array}\right.
$$

Whereas

$$
r_{k j}=r_{k-1, j}-r_{k k} r_{k-1, k-j} \quad \text { for } \mathrm{j}=1,2, \ldots, \mathrm{k}-1
$$

It means that " $r_{k j}$ " represented ACF of timeseries by lag " $j$ " time units. Therefore, the intervening observation between " $k$ " and " $j$ " eliminated. Whereas standard error of PACF.

$S_{r_{k k}}=\sqrt{\frac{1}{n}}$ 


\subsection{Parameter Estimation}

The timeseries parameter can be estimated by Sample moment estimation, Linear least square method, Max likelihood estimation(Generalized), Method of moments, Bayesian estimation or Kalman filtering However, the least square method is frequently used to estimate the $M A$ component. Sometimes max likelihood function is used to define the probability of observed data.

\subsection{Diagnostic checking}

After the model identification mostly AIC (Akaike's information criterion) and BIC (Bayesian information criterion) are performed and the least value of AIC and BIC is considered as the best fitted model.(Reza Ghanbarpour et al. 2010)

$$
\mathrm{AIC}=-2 \ln (\mathrm{L})+2 \mathrm{k}
$$

whereas $\mathrm{L}=$ likelihood function

$\mathrm{K}=$ number of parameters to be estimated

$$
\mathrm{BIC}=-2 \ln (\text { Max. Likelihood })+\mathrm{Tp} \ln (\mathrm{n})
$$

whereas L=likelihood function

$\mathrm{K}=$ number of parameters to be estimated

$\mathrm{n}=$ number of terms

\subsection{Forecasting}

The h-period ahead forecast based on an $\operatorname{ARIMA}(p, d, q)$ model where the $\mathrm{d}=0$ is given by

$$
\hat{y}_{t+h}=\hat{\delta}+\hat{\varphi}_{1} y_{t+h-1}+\ldots . \hat{\varphi}_{p} y_{t+h-p}+e_{t+h}-\hat{\theta}_{1} e_{t+h-1}-\ldots . . \hat{\theta}_{q} e_{t+h-q}
$$

$Y_{t+h}$ terms are replaced with the estimated values until the last observed values.

\subsection{Identification of $\mathrm{p}$ and $\mathrm{q}$ terms}

ACF and PACF was used to identify the $p$ and $q$ terms.

\subsection{Reservoir operation management}

After forecasting the hydrometeorological timeseries, reservoir operation was performed on monthly time step. The forecasted reservoir operation represented the future expected reservoir water levels, reservoir storages, reservoir shortage excess periods. This information can be helpful to develop and improve the reservoir policies. Reservoir elevation curve represents the water levels of reservoir. The inflows and precipitation play important role to raise the water levels where as outflows, evaporations and water demands decreased the water levels in the reservoir. Reservoir release curve represents the reservoir outflows. In most of cases, reservoir releases are dependent on the downstream water demands. Sometime inflows were high and water levels were increased abruptly. To avoid such situations, excess water can be released than the downstream demands.

\section{Results and Discussions}

The historical hydrometeorological time series of Mangla reservoir from 1991 to 2015 is used to develop the ARIMA model. Mangla watershed has snow melting effect in the contribution of stream flows. Mangla inflow time series is nonstationary time series. It means that its mean, variances, and covariance of time series are not constant. It is compulsory to convert into stationary because ARIMA model could not perform analysis on to the nonstationary timeseries.

Several trials are performed to convert into stationary. First, take first difference, second order difference and so on. Unfortunately, after differencing it is not converted into stationary. Therefore, as the second option log transformation is used. After log transformation the inflow time series are converted into stationary. Further analysis is performed on stationary time series. 


\subsection{ACF and PACF}

Precipitation timeseries consisted of abruptly changes which creates different scenarios. Therefore, ACF (Autocorrelation function) and PACF (Partial autocorrelation function) are drawn as shown in Figure 3. This figure shows high peak values which is the causes of precipitation timeseries random changes. From Figure, it is cleared that the nine values were significant out of first 12 values. After this all the values were remained in the limit. The maximum value of ACF was 0.5 which occurred after lags 11 . In the Figure 3, PACF of precipitation times series were presented. Most of values were remained in the range of confidence limit. The maximum value was 0.3 which occurred after lags1.The evaporation time series ACF and PACF are also shown in Figure 3. ACF and PACF spikes are change after high lag values and lies in the limit of 5 percent confidence interval. Therefore, AR terms is selected 9 and MA terms are selected 19. ACF and PACF of inflow timeseries is given in Figure 3.

\section{[Insert Fig. 3]}

\subsection{Calibration and Validation}

The hydrometeorological timeseries of Mangla reservoir was divided into two periods for calibration and validation. The calibration period was selected from 1991 to 2005; whereas, validation period from 2006-2015. In calibration and validation of ARIMA model the simulated hydrometeorological timeseries of inflows, evaporation and precipitation timeseries were compared with the observed values. The $\mathrm{R}^{2}$, MAE and RMSE values of inflow timeseries was evaluated and their values were $0.89,113$ and 209, respectively. Whereas the observed precipitation timeseries were also compared with the ARIMA model simulated values and their $\mathrm{R}^{2}$, MAE and RMSE value were 0.81, 28 and 43, respectively. The values of $\mathrm{R}^{2}, \mathrm{MAE}$ and RMSE of evaporation timeseries were $0.78,27$ and 39 , respectively.

In validation period (2006-2010) the simulated timeseries were compared with observed data and the value of $\mathrm{R}^{2}$, MAE and RMSE were evaluated. For the inflows timeseries, the value of $\mathrm{R}^{2}$, MAE and RMSE were $0.85,145$ and 195, respectively. Whereas the $\mathrm{R}^{2}, \mathrm{MAE}$ and RMSE of precipitation timeseries were $0.83,14.5$ and 31.7 , respectively. The value of $\mathrm{R}^{2}, \mathrm{MAE}$ and RMSE of evaporation timeseries is $0.88,21$ and 31 , respectively.

\subsubsection{Calibration of Inflow, precipitation and evaporation timeseries}

On the basis of RMSE, $\mathrm{R}^{2}$ and MAE the inflow timeseries has best fitted seasonal ARIMA model structure of $(1,0,0)(2,1,2)_{12}$. The model simulated and observed flows are presented in Figure 4(a). The simulated values are compared with the observed flows. Most of peaks are found consistent with the observed flows.

Precipitation timeseries has many fluctuations and steep peaks. Precipitation timeseries was less smooth as compared to the inflows and evaporation. The best fit model structure for the precipitation timeseries was $(14,1,15)$. The model simulated and observed flows are presented in Figure 4(b). During the calibration of ARIMA model the AR value of 14 was selected.

ARIMA model structure of $(9,1,19)$ was best fitted for evaporation timeseries. In calibration period, i.e., 19902005, the simulated data and observed data were compared and the results are presented in Figure 4(C). It is clear from Figure 4 that the first two peaks of observed evaporation were lower compared to simulated timeseries. Afterwards, observed data peaks were higher than the simulated data. The maximum difference of data was observed in the year 1998. In 1998, the maximum simulated value was $456 \mathrm{~mm}$ whereas the observed value was $343 \mathrm{~mm}$

\subsubsection{Validation of Inflow, Precipitation and evaporation timeseries}

The period of 1991-2015 was selected as the validation period for inflow timeseries. In the validation period, most of the peaks of observed data were slightly above the simulated timeseries. In the inflow timeseries, the seasonal trend was more prominent. Therefore, seasonal ARIMA model structure was found best fitted for the inflow timeseries. It was compared with the observed flows and found the values of $\mathrm{R}^{2}$, RMSE, MAE are $0.85,195$ and 145 , respectively. After the validation of these results the same ARIMA model structure is used to forecast the inflow timeseries for the period of 2016-2030. In the validation period 2005-2015, the first peak of simulated flows is slightly higher than the observed flows which is shown in Figure 4(a). In the 2007 the max value of inflow is 1961 cumecs whereas in the same year the simulated flows max value is 1280 . The next year 2008 the observed inflows are lower than the simulated flows.

In the validation period, precipitation peaks were fluctuated between values of 150 to 330 . The extreme trend of precipitation was decreased from 2006 to 2010 and after this it was increased. Whereas the last two years of validation period the simulated peaks were higher than the observed timeseries. After the comparison of the value 
of RMSE and MAE were 31.7 and 21, respectively. Validation of observed and simulated precipitation is shown in Figure 4(b).

During the validation period (2006-2015) of evaporation timeseries, the same ARIMA model structure was used as that of during the calibration process and found that the simulated evaporation timeseries were comparable with the observed evaporation timeseries. The first three peaks of timeseries were overlapped with the simulated values. The values of statistical parameters of MAE and RMSE values were found as 14.5 and 31, respectively. Some sudden rise of curve in the observed values were found slightly deviating with simulated values. Validation of evaporation is shown in Figure 4(c).

\section{[Insert Fig. 4]}

\subsection{Forecasting of inflow, precipitation and evaporation timeseries}

After the calibration and validation process, same ARIMA model structure was used to forecast the inflow timeseries for the period of 2015-2030. It is clear from Figure 5, that the maximum flows are predicted in the year 2018-19. Whereas the lowest flows are expected in the year 2023. This forecasted inflows timeseries was used in the reservoir operation. After this, the forecasted rule curve of reservoir was determined, and water shortage was also determined. These predictions may help the reservoir operators and managers to fulfil the water demands.

To extrapolate the precipitation timeseries up to 2030, same ARIMA model structure of $(14,1,15)$ was used as adopted during the model calibration and validation. The simulated results are showing many similarities to the historical precipitation timeseries data. Most of peak values were observed less than 300. The fluctuation of timeseries were steep as the historical data of precipitation timeseries has many peak values. The highest peak was expected in the year 2027.

After the validation of evaporation timeseries, ARIMA model structure of $(9,1,19)$ was adopted. These forecasted timeseries were used for the reservoir operation. These forecasted timeseries were presented in the following Figure 5. Highest peak of in the evaporation timeseries was observed in the month of June because of the highest temperature being observed in this month.

The simulated timeseries was used for reservoir operation and forecasted water shortage and rule curves of reservoir were determined. These predictions of future water availability and demands may be helpful for reservoir operators and managers to regulate the reservoir efficiently.

\section{[Insert Fig. 5]}

\subsection{Reservoir Operation}

Reservoir operators and managers are very conscious to its safety and efficiency. To enhance its benefits future aspects are also taken into considerations. Therefore, ARIMA model was used for forecasting of inflows, precipitation, and evaporation timeseries. After forecasting the hydrometeorological timeseries, reservoir operation was performed on monthly time step. The forecasted reservoir operation represented the future expected reservoir water levels, reservoir storages, reservoir shortage excess periods. This information can be helpful to develop and improve the reservoir policies.

Reservoir elevation curve represents the water levels of reservoir. The inflows and precipitation play important role to raise the water levels where as outflows, evaporations and water demands decreased the water levels in the reservoir. Sudden rise and drawdown are considered dangerous for reservoir. Such conditions may create the cracks in the reservoir body.

In the Figure 6(a), reservoir elevation curve is presented. Most of peaks in the curve have one-year difference which is safe and smooth changes in the water levels.

Reservoir release curve represents the reservoir outflows. In most of cases, reservoir releases are dependent on the downstream water demands. Sometime inflows were high and water levels were increased abruptly. To avoid such situations, excess water can be released than the downstream demands. So that water levels remained in the safe conditions. Figure 6(b) presents the reservoir releases during period of 2016-2030. The y axis represents the quantity of water in million cubic meters $\left(\mathrm{Mm}^{3}\right)$ and $\mathrm{x}$-axis represents the time scale. The reservoir operation was performed on monthly time step; therefore, these values were represented monthly basis.

The quantity of water stored in the reservoir is represented by the reservoir storage curves. When reservoir storages were high then the water was available to fulfil the downstream water requirements. Figure 6(b) represents the 
reservoir storages. During the period of (2016-2020) water is available to fulfil the water demands. However, during the period of (2021-2026) the reservoir remains partially filled. In the year of 2027, excess water is available for storages.

When the downstream water demands are not fulfilled it is represented the as water shortage period in percentage. With the rapid increase in population water demands for various purposes are increasing at alarming rate in Pakistan. Whereas, water storages are remained same, to fulfil these ever-increasing water demands. Therefore, water shortages are increased. Another aspect of sedimentation is also decreasing the water storages. In the Figure 6(c), water shortages were presented. During the low flow periods the water shortage were found higher. Another aspect is the high-water demand periods. When the irrigation demands are higher than the amount of water is required more and causing the water shortages. The average water shortage of forecasted reservoir operation is $14 \%$ during the period of 2016-2030.

\section{[Insert Fig. 6]}

\section{Conclusions}

In this study ARIMA model is used to forecast the hydro-meteorological time series of Mangla reservoir. Seasonal ARIMA model $(1,0,0)(2,1,2)_{12}$ is best fitted for the inflow time series. For smoothening the time series (ln) $\log$ transformation is used. After comparison of results with the observed inflows it is highly accurate based on $\mathrm{R}^{2}$, RMSE and MAE. Whereas Precipitation and evaporation time series are not periodic. therefore, ARIMA model $(14,1,15)$ is best fitted for Precipitation and $(9,1,19)$ is selected for evaporation time series. After forecasting of these time series up to 2030, reservoir operation of Mangla is performed on the monthly time step. The forecasted rule curves are developed and the water shortage up to 2030 is determined. The average water shortage for this period is 14 percent

The forecasted hydro-meteorological time series data may support the reservoir operators and managers for developing the efficient real-time reservoir operation policies and strategies and optimization of reservoir.

\section{Acknowledgments}

I am deeply gratitude of WAPDA Pakistan for providing of data and CEWRE UET Lahore for the cooperation and motivation for completing this study.

Authors' Contributions: All authors contributed to the study conception. Material preparation, data collection and analysis were performed by H. U. Rahman, I. Ahmad, F. Haq, M. Waseem and J. Zhang. This manuscript was written by H. U. Rahman, I. Ahmad, and F. Haq, M. Waseem and reviewed by J. Zhang. All authors read and approved the final manuscript.

Funding: No funding was received to assist with the preparation of this manuscript.

Data Availability: The data used to support the findings of this study are available from the corresponding author upon reasonable request.

\section{Declarations}

Conflicts of Interest: The authors declared that they have no conflicts of interest to this work.

Ethics Approval: Not applicable

Consent to Participate: Not applicable

Consent to Publish: Not applicable 
Code Availabilty: The models or codes used to develop this study are available from the corresponding author upon reasonable request.

\section{References}

Adhikary, Sajal Kumar, Md. Mahidur Rahman, and Ashim Das Gupta. 2012. "A Stochastic Modelling Technique for Predicting Groundwater Table Fluctuations with Time Series Analysis." International Journal of Applied Science and Engineering Research 1 (2). https://doi.org/10.6088/ijaser.0020101024.

Adnan, Rana Muhammad, Xiaohui Yuan, Ozgur Kisi, and Valetin Curtef. 2017. "Application of Time Series Models for Streamflow Forecasting." Civil and Environmental Research 9 (3): 56-63. www.iiste.org.

Ahmad, Shamshad, Iqbal H Khan, and B.P Parida. 2001. "Performance of Stochastic Approaches for Forecasting River Water Quality." Water Research 35 (18): 4261-66. https://doi.org/10.1016/S0043-1354(01)00167-1.

Bahremand, Abdolreza, and Florimond De Smedt. 2010. "Predictive Analysis and Simulation Uncertainty of a Distributed Hydrological Model." Water Resources Management 24 (12): 2869-80. https://doi.org/10.1007/s11269-010-9584-1.

Box, George E.P., Gwilym M. Jenkins, Grogery C. Reinsel, and Greta M. Ljung. 2015. Time Series Analysis: Forecasting and Control. 5th ed. Wiley and Sons.

Brown, Linfield C., and Paul Mac Berthouex. 2002. Statistics for Environmental Engineers. 2nd ed. CRC Press.

Gocheva-Ilieva, Snezhana Georgieva, Atanas Valev Ivanov, Desislava Stoyanova Voynikova, and Doychin Todorov Boyadzhiev. 2014. "Time Series Analysis and Forecasting for Air Pollution in Small Urban Area: An SARIMA and Factor Analysis Approach." Stochastic Environmental Research and Risk Assessment 28 (4): 1045-60. https://doi.org/10.1007/s00477-013-0800-4.

Koutsoyiannis, Demetris. 2000. "A Generalized Mathematical Framework for Stochastic Simulation and Forecast of Hydrologic Time Series." Water Resources Research 36 (6): 1519-33. https://doi.org/10.1029/2000WR900044.

Kurunç, Ahmet, Kadri Yürekli, and Osman Çevik. 2005. "Performance of Two Stochastic Approaches for Forecasting Water Quality and Streamflow Data from Yeşilurmak River, Turkey." Environmental Modelling \& Software 20 (9): 1195-1200. https://doi.org/10.1016/j.envsoft.2004.11.001.

Lawrance, A. J., and N. T. Kottegoda. 1977. "Stochastic Modelling of Riverflow Time Series.” Journal of the Royal Statistical Society. Series A (General) 140 (1): 1. https://doi.org/10.2307/2344516.

Modarres, R., and T. B. M. J. Ouarda. 2013. "Modelling Heteroscedasticty of Streamflow Times Series.” Hydrological Sciences Journal 58 (1): 54-64. https://doi.org/10.1080/02626667.2012.743662.

Musa, J.J. 2013. "Stochastic Modelling of Shiroro River Stream Flow Process." American Journal of Engineering Research, no. 06: 49-54. 
Pulido-Calvo, I., J. Roldán, R. López-Luque, and J. C. Gutiérrez-Estrada. 2003. "Demand Forecasting for Irrigation Water Distribution Systems." Journal of Irrigation and Drainage Engineering 129 (6): 422-31. https://doi.org/10.1061/(ASCE)07339437(2003)129:6(422).

Reza Ghanbarpour, M., Karim C. Abbaspour, Goudarz Jalalvand, and Ghodsieh Ashtiani Moghaddam. 2010. "Stochastic Modeling of Surface Stream Flow at Different Time Scales: Sangsoorakh Karst Basin, Iran.” Journal of Cave and Karst Studies 72 (1): 1-10. https://doi.org/10.4311/jcks2007ES0017.

Sarwar, M. 2013. "Reservoir Life Expectancy in Relation to Climate and Land-Use Changes : Case Study of the Mangla Reservoir in Pakistan The University of Waikato." THE UNIVERSITY OF WAIKATO.

Tayyab, Muhammad, Jianzhong Zhou, Xiaofan Zeng, and Rana Adnan. 2016. "Discharge Forecasting By Applying Artificial Neural Networks At The Jinsha River Basin, China." European Scientific Journal, ESJ 12 (9): 108. https://doi.org/10.19044/esj.2016.v12n9p108.

Valipour, Mohammad, Mohammad Ebrahim Banihabib, Seyyed Mahmood, and Reza Behbahani. 2013. "Comparison of the ARMA, ARIMA, and the Autoregressive Artificial Neural Network Models in Forecasting the Monthly Inflow of Dez Dam Reservoir." Journal of Hydrology 476: 433-41. https://doi.org/10.1016/j.jhydrol.2012.11.017.

Wang, Jing, Liyuan Zhang, Wen Zhang, and Xiaodi Wang. 2019. "Reliable Model of Reservoir Water Quality Prediction Based on Improved ARIMA Method." Environmental Engineering Science 36 (9): 1041-48. https://doi.org/10.1089/ees.2018.0279.

Wang, Sufen, Shaozhong Kang, Lu Zhang, and Fusheng Li. 2008. "Modelling Hydrological Response to Different Land-use and Climate Change Scenarios in the Zamu River Basin of Northwest China." Hydrological Processes 22 (14): 2502-10. https://doi.org/10.1002/hyp.6846.

Xu, Jianhua, Yaning Chen, Weihong Li, Qin Nie, Chunan Song, and Chunmeng Wei. 2014. "Integrating Wavelet Analysis and BPANN to Simulate the Annual Runoff With Regional Climate Change: A Case Study of Yarkand River, Northwest China." Water Resources Management 28 (9): 2523-37. https://doi.org/10.1007/s11269-014-0625-z.

Zamani Sabzi, Hamed, James Phillip King, and Shalamu Abudu. 2017. "Developing an Intelligent Expert System for Streamflow Prediction, Integrated in a Dynamic Decision Support System for Managing Multiple Reservoirs: A Case Study." Expert Systems with Applications 83 (October): 145-63. https://doi.org/10.1016/j.eswa.2017.04.039. 
Figures

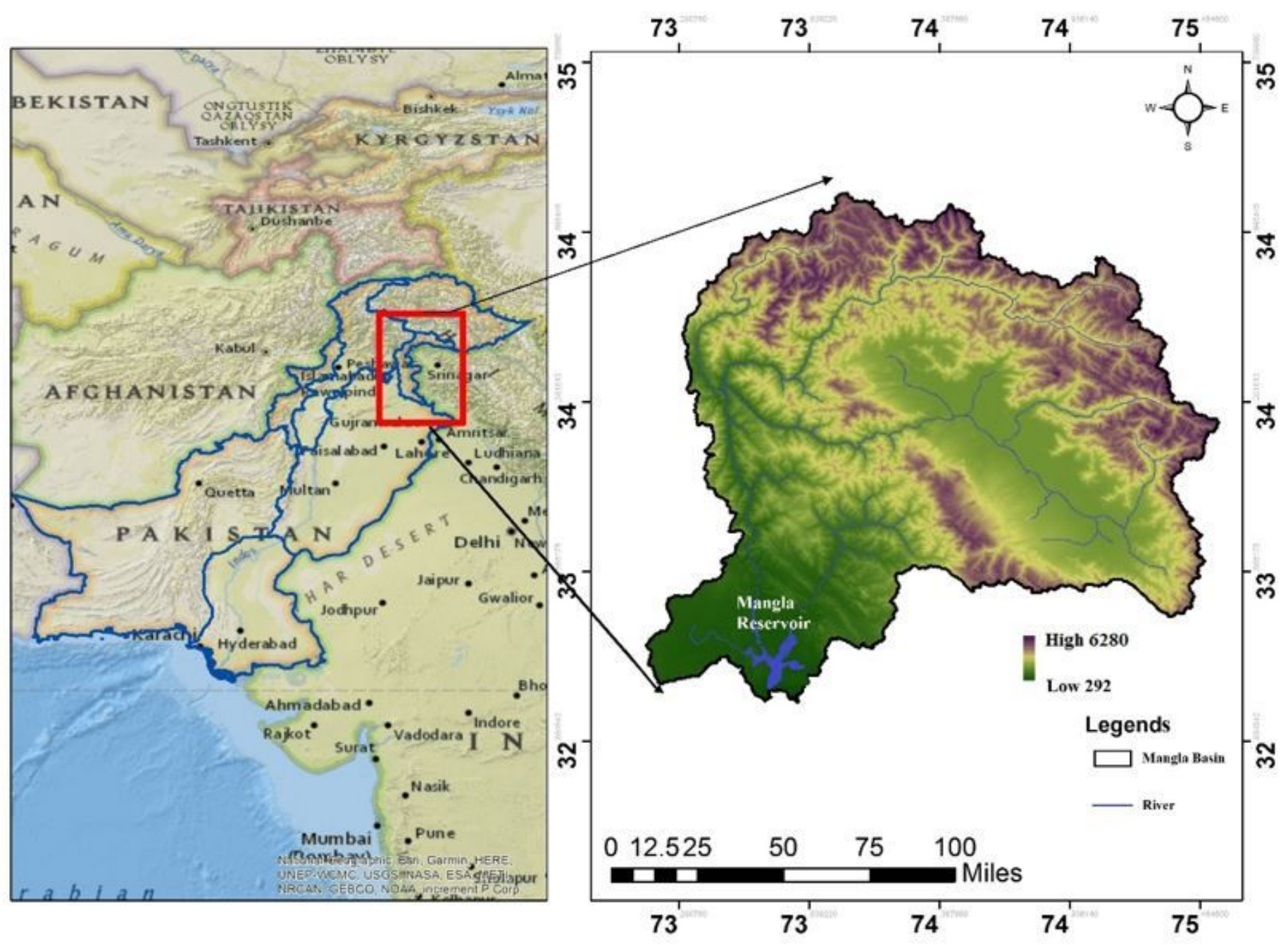

Figure 1

Mangla watershed and reservoir 


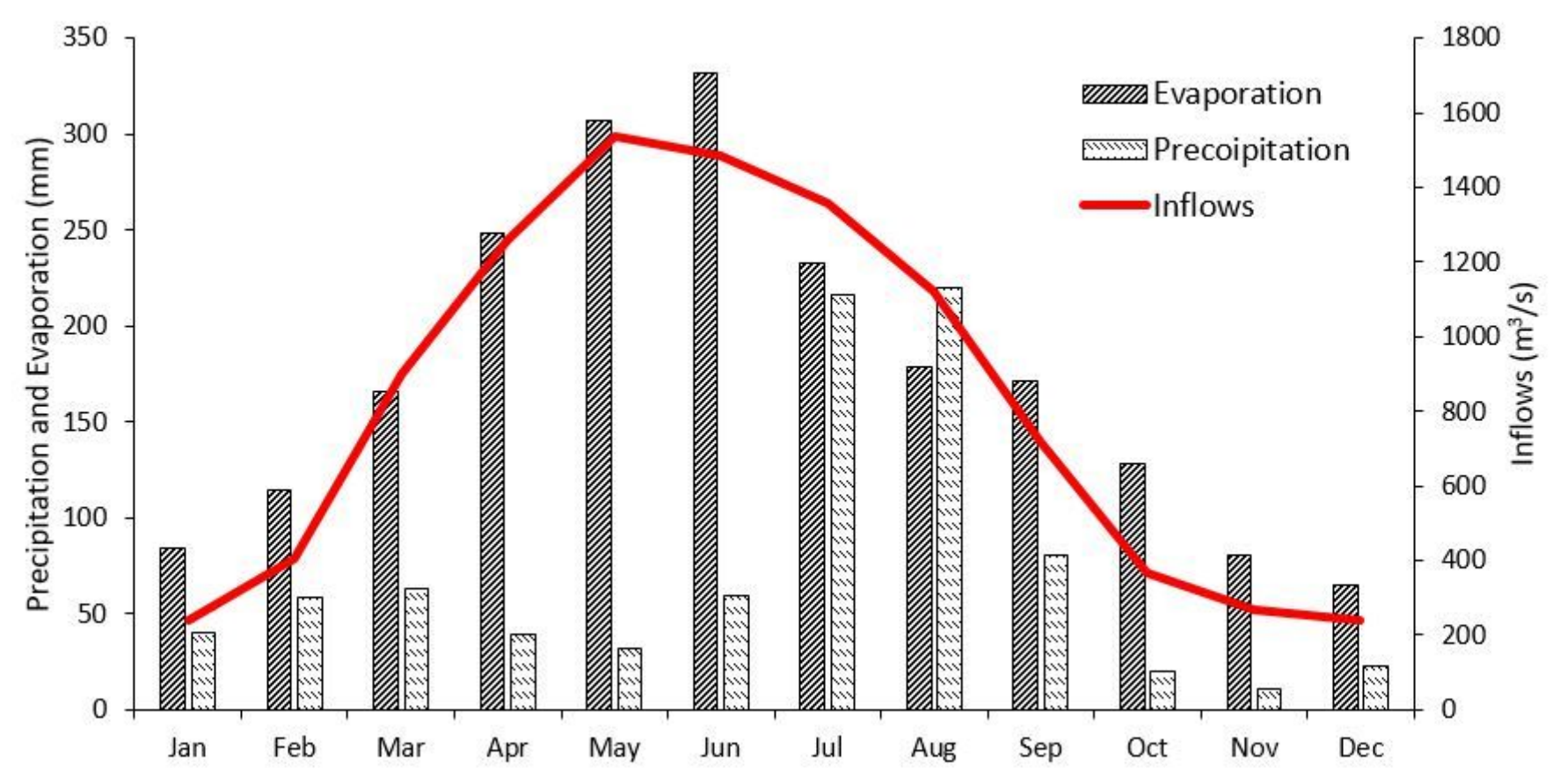

Figure 2

(a) mean monthly inflows at Mangla reservoir (b) mean monthly precipitation at Mangla 

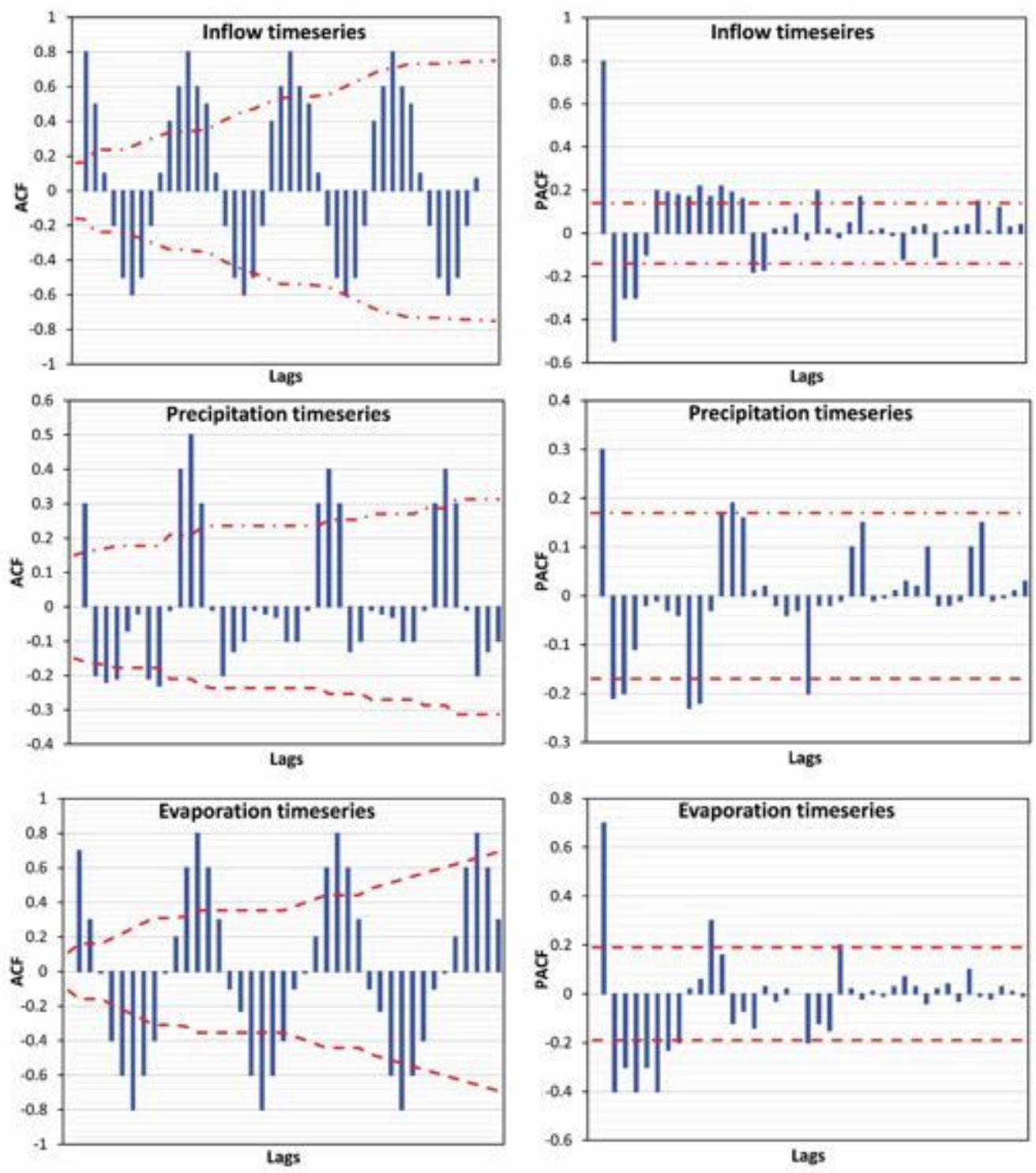

Figure 3

ACF and PACF of inflow, precipitation and evaporation timeseries 

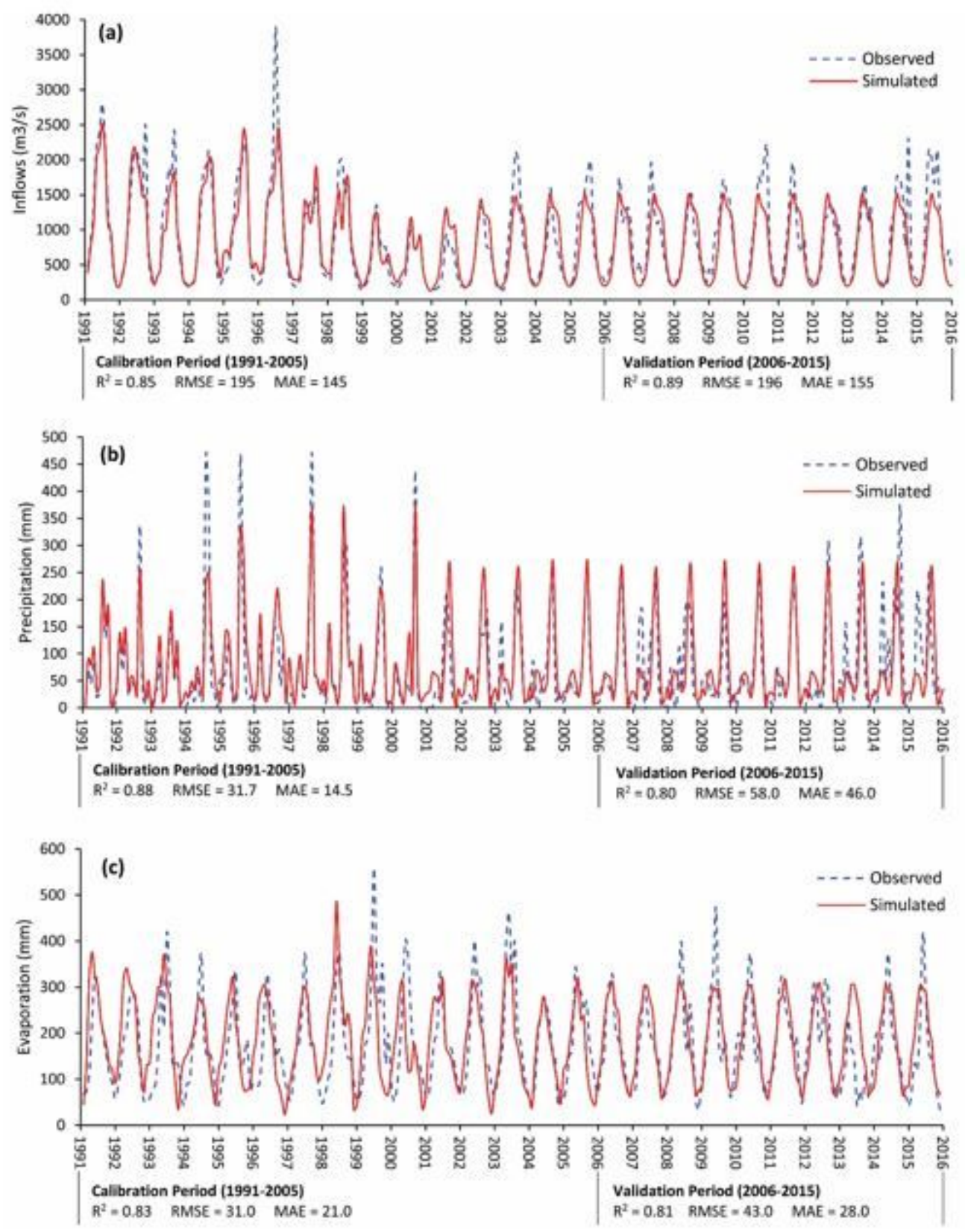

Figure 4

Calibration and Validation of Observed and Simulated data of ARIMA Model during the period 2006-2015 

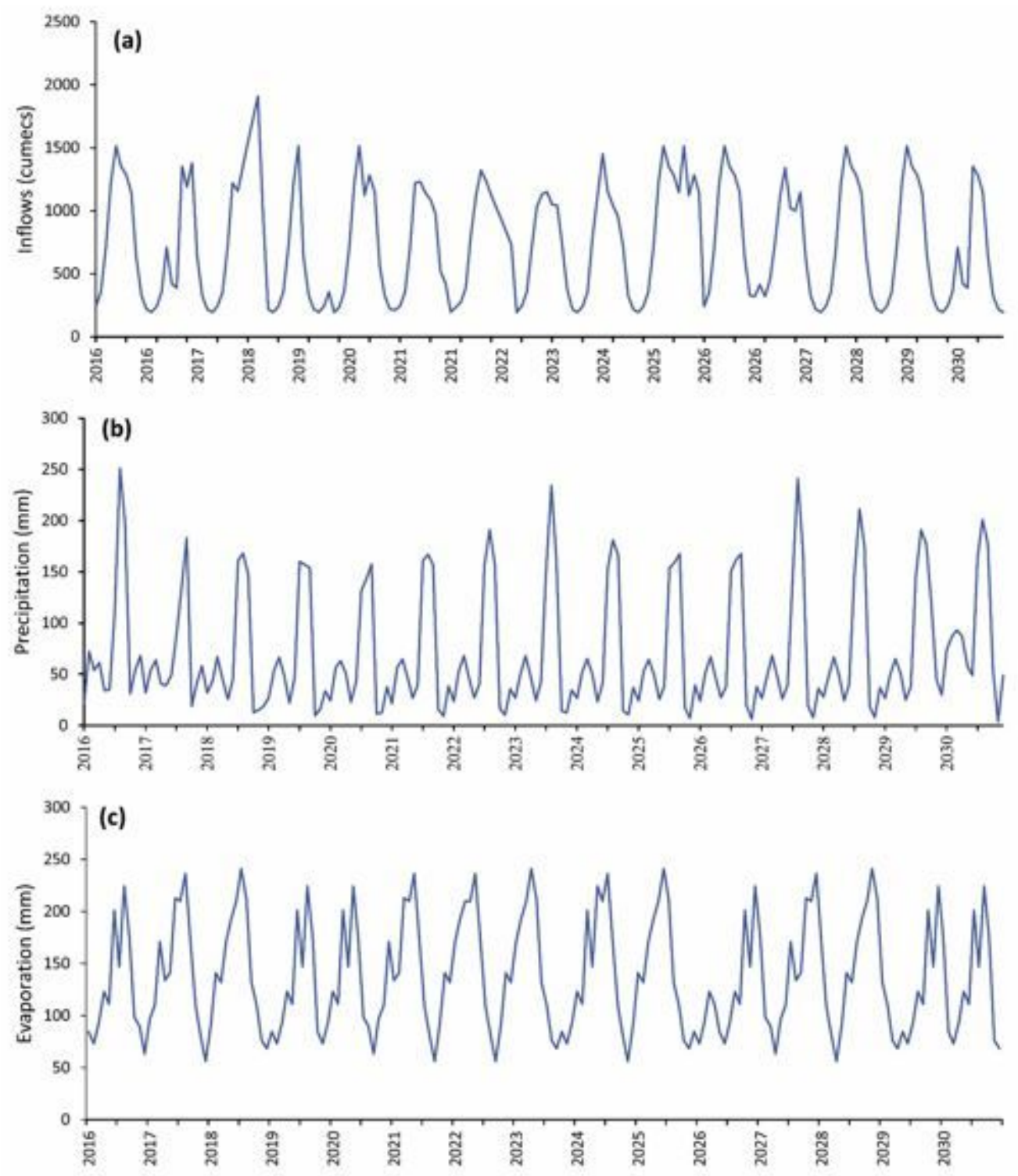

Figure 5

Simulated data of ARIMA Model during the period 2016-2030 

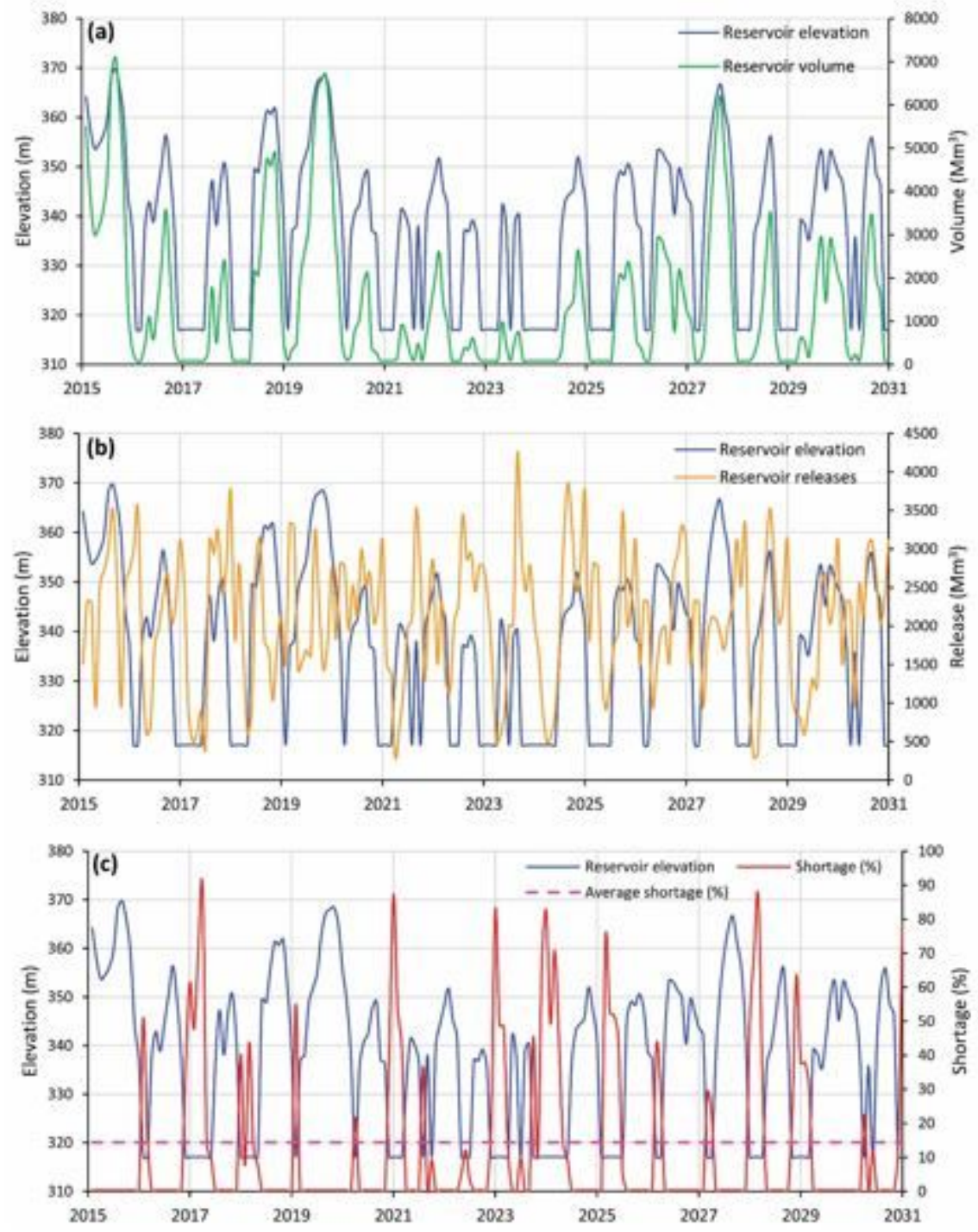

Figure 6

(a) Mangla reservoir levels (b) Mangla reservoir volume (c) Reservoir shortage curve for the period of 2016-2030 